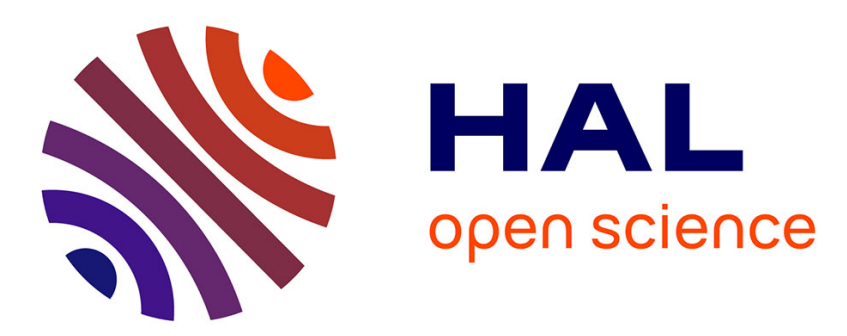

\title{
A small molecule that mimics the metabolic activity of copper-containing amine oxidases (CuAOs) toward physiological mono- and polyamines
}

Martine Largeron, Maurice-Bernard Fleury, Margherita Strolin Benedetti

\section{- To cite this version:}

Martine Largeron, Maurice-Bernard Fleury, Margherita Strolin Benedetti. A small molecule that mimics the metabolic activity of copper-containing amine oxidases ( $\mathrm{CuAOs)} \mathrm{toward} \mathrm{physiological}$ mono- and polyamines. Organic \& Biomolecular Chemistry, 2010, 8 (16), pp.3796. 10.1039/c004501b . hal-02384876

\section{HAL Id: hal-02384876 https://hal.science/hal-02384876}

Submitted on 22 Jan 2021

HAL is a multi-disciplinary open access archive for the deposit and dissemination of scientific research documents, whether they are published or not. The documents may come from teaching and research institutions in France or abroad, or from public or private research centers.
L'archive ouverte pluridisciplinaire HAL, est destinée au dépôt et à la diffusion de documents scientifiques de niveau recherche, publiés ou non, émanant des établissements d'enseignement et de recherche français ou étrangers, des laboratoires publics ou privés. 


\title{
A small molecule that mimics the metabolic activity of copper-containing amine oxidases (CuAOs) toward physiological mono- and polyamines $\uparrow$
}

\author{
Martine Largeron, ${ }^{* a}$ Maurice-Bernard Fleury ${ }^{a}$ and Margherita Strolin Benedetti ${ }^{b}$
}

Accepted 01 Jun 2010

Primary aliphatic biogenic amines have been successfully oxidized using a quinonoid species that mimics the metabolic activity of copper-containing amine oxidase $(\mathrm{CuAO})$ enzymes. Especially, high catalytic performances were observed with aminoacetone, a threonine catabolite, and methylamine, a metabolite of adrenaline, and with the primary amino groups of putrescine and spermidine, both decarboxylation products of ornithine and S-adenosylmethionine. Furthermore, contrary to flavine adenine dinucleotide (FAD)-dependent amine oxidase enzymes, no activity was found toward secondary and tertiary amines.

\footnotetext{
${ }^{a}$ UMR 8638 CNRS-Université Paris Descartes, Synthèse et Structure de Molécules d'Intérêt Pharmacologique, Faculté des Sciences Pharmaceutiques et Biologiques, 4 avenue de l'Observatoire, 75270 Paris cedex 06, France. E-mail: martine.largeron@parisdescartes.fr; Fax: + 33144073588; Tel: + 33153739646.

${ }^{b}$ UCB Pharma SA, 420 rue d'Estienne d'Orves, 92705 Colombes, France

$\uparrow$ Electronic supplementary information (ESI) available : Full experimental procedures and NMR spectra of isolated products. See DOI:10.1039/c004501B
} 


\section{Introduction}

Amine oxidases (AOs) are ubiquitous enzymes which metabolize various monoamines, diamines and polyamines of endogenous, dietary or xenobiotic origin. ${ }^{1}$ AOs have been divided into two main categories depending on the cofactor involved and on the catalytic mechanism. One class, which encompasses monoamine oxidases (MAO A and MAO B) and polyamine oxidases (PAOs), is characterized by the presence of flavine adenine dinucleotide (FAD) as the redox cofactor (Fig. 1). ${ }^{2}$ The second class, named copper amine oxidases (CuAOs), is represented by enzymes which possess tightly bound $\mathrm{Cu}^{\mathrm{II}}$ and a quinone residue as the redox cofactor. ${ }^{3}$ Except for lysyl oxidases, whose active site has been identified as lysine tyrosylquinone (LTQ), ${ }^{4} \mathrm{CuAOs}$ use as redox cofactor, the tyrosine-derived 2,4,5trihydroxyphenylalanine quinone, also named topaquinone (TPQ). ${ }^{5}$ Most CuAOs are sensitive to inhibition by semicarbazide so that, in the literature, they are generally referred to as semicarbazide-sensitive amine oxidases (SSAOs) (EC 1.4.3.6.). Recently, it has been suggested to reclassify them as primary amine oxidases (PrAOs), enzymes oxidizing primary monoamines with little or no activity toward diamines (EC 1.4.3.21), and as diamine oxidases (DAOs), enzymes oxidizing diamines such as histamine and also some primary monoamines (EC 1.4.3.22). Both enzymes are inactive toward secondary and tertiary amines. ${ }^{6}$

Interest in human enzymes of the CuAOs class has increased in recent years driven by the recent discovery that the human vascular adhesion protein-1 (VAP-1), which regulates leucocyte trafficking, belongs to the CuAOs family. ${ }^{7}$ Although DAO is mainly located intracellularly, PrAO enzymes are located in plasma membranes of various tissues and in blood plasma, and their role is to regulate levels of endogenous and xenobiotic mono- and polyamines, by catalyzing their oxidative deamination with the concomitant production of hydrogen peroxide, ammonia and aldehyde. Each of these products is potentially nasty, since hydrogen peroxide can act as a source of reactive oxygen species (ROS), while ammonia and aldehyde products are known to be toxic in a number of systems. ${ }^{8}$

Activities of $\mathrm{CuAOs}$ are mostly increased in various human disorders, including type 1 and type 2 diabetes, congestive heart failure, atherosclerosis, liver cirrhosis, Alzheimer's disease and many inflammation-associated diseases. ${ }^{9}$ For example, PrAOs catalyze the oxidative deamination of methylamine, resulting from the metabolism of adrenaline by MAO, and of aminoacetone, a threonine and glycine catabolite. These endogenous monoamines respectively generate formaldehyde and methylglyoxal as highly reactive side products, then 
contributing to the formation of advanced-glycation end products (AGEs), which are associated with vascular complications of diabetes. ${ }^{10}$ These aldehydes are also capable of inducing protein cross-linking. Especially, they are able of enhancing the formation of $\beta$ amyloid misfolding oligomers and protofibrils, but also of increasing the size of the aggregates, two phenomena closely associated with Alzheimer's disease. ${ }^{11}$ Consequently, it has been recognized that PrAO inhibitors might have potential therapeutic value. ${ }^{8 c}$ In this respect, a potent orally active and selective inhibitor of PrAO activity (LJP 1586) is currently under investigation as a potential anti-inflammatory agent. ${ }^{12}$

On the other hand, the natural polyamines such as putrescine, spermidine or spermine, which are formed from the decarboxylation products of ornithine and S-adenosyl-methionine, are also endogenous substrates for CuAO enzymes. ${ }^{13}$ In cancerous cells, they are present at elevated levels as compared to normal tissues, because of enhanced putrescine synthesis from ornithine by ornithine decarboxylase, but also due to increased uptake of polyamines. Consequently, by delivering CuAOs into cancerous cells, the cytotoxic products of polyamines oxidation, hydrogen peroxide and aldehydes, could be produced in situ for selective killing of the same cells. The utilization of CuAOs in anticancer therapy has been recently suggested as a promising strategy to overcome multi drug resistance of cancer. ${ }^{14}$

Through the utilization of synthetic models of TPQ and LTQ cofactors and using benzylamine as the substrate, ${ }^{15}$ it has been established that TPQ catalyzes the conversion of a primary amine substrate into an aldehyde through a classical ping pong mechanism. ${ }^{16}$ However, these models cofactors failed to oxidize nonactivated primary amines under the same experimental conditions, that are in the absence of a metal ion. In contrast, a few years ago, we found that electrogenerated $o$-iminoquinone $\mathbf{1}_{\mathbf{o x}}$ (Figure 1) behaved as an effective biomimetic catalyst for the oxidation of primary aliphatic monoamines, under metal free conditions. $^{17}$ The catalytic cycle produced the reduced catalyst $\mathbf{1}_{\text {red }}$ and $\mathrm{N}$ alkylidenealkylamine as the product of amine oxidation (Scheme 1). This process is the analog of the above mentioned ping pong mechanism ${ }^{16}$, but $\mathrm{N}$-alkylidenealkylamine was generated instead of aldehyde, because methanol was used as the solvent, in place of aqueous solution. Consequently, no hydrolysis into aldehyde took place during the catalytic process. Importantly, the presence of the active 2-hydroxyl group, which was engaged in an intramolecular hydrogen bond with the imine nitrogen to form a highly reactive Schiff base cyclic transition state $\mathbf{1}$ 'ox, constituted a prerequisite to the development of the catalytic process (Scheme 1). ${ }^{17 \mathrm{c}}$ 
In this paper, we further investigate the catalytic efficiency of the quinonoid electrocatalyst $\mathbf{1}_{\mathbf{0 x}}$ using different endogenous mono- and polyamines, which are substrates for $\mathrm{CuAO}$ enzymes, and we demonstrate that $\mathbf{1}_{\mathbf{0 x}}$ exhibits the same substrate specificity as the $\mathrm{CuAO}$ enzymes, whereas markedly differing from FAD-dependent amine oxidase enzymes.

\section{Results and Discussion}

First, we examined the catalytic efficiency of $\mathbf{1}_{\mathbf{o x}}$ toward different primary monoamines which are substrates for PrAO enzymes. Benzylamine, which is a good exogenous substrate, was used as the reference compound. Upon optimization, we have previously shown that a combination of $5 \mathrm{mmol}$ of benzylamine with $0.1 \mathrm{mmol}$ of the reduced catalyst $\mathbf{1}_{\text {red }}$, which corresponds to $2 \mathrm{~mol} \%$ of the $o$-iminoquinone catalyst $\mathbf{1}_{\mathbf{o x}}$, is ideal for the reaction. ${ }^{17 \mathrm{c}}$ When the controlled potential of the Pt anode was fixed at $+0.6 \mathrm{~V}$ vs. SCE, which is at a potential for which $\mathbf{1}_{\text {red }}$ could be oxidized to the $o$-iminoquinone species $\mathbf{1}_{\mathbf{o x}}$, the anodic current remained constant for a long time, and the current efficiency obtained by the electrolysis for $7 \mathrm{~h}$ was $100 \%$, indicating that no side reaction took place under the experimental conditions used (Table 1, entry 1). These results indicated that the $\mathbf{1}_{\text {red }} / \mathbf{1}_{\mathbf{~ o x}}$ system behaved as a redox mediator for the indirect electrochemical oxidation of benzylamine to the corresponding $\mathrm{N}$ benzylidenebenzylamine, according to reaction scheme 1. After exhaustive controlled potential electrolysis, $N$-benzylidenebenzylamine was isolated by converting to the 2,4dinitrophenylhydrazone (DNPH), obtained upon workup of the oxidized solution with 2,4dinitrophenylhydrazine under aqueous acidic conditions (See Experimental). Note the yield could not exceed $50 \%$, because $5 \mathrm{mmol}$ of benzylamine only gave $2.5 \mathrm{mmol}$ of $\mathrm{N}$ benzylidenebenzylamine. Finally, the $\mathbf{1}_{\mathbf{o x}}$-mediated oxidation of benzylamine reference compound afforded the corresponding $N$-benzylidenebenzylamine, in quantitative yield since the current efficiency and the yield of DNPH reached $100 \%$ and $50 \%$, respectively. In contrast to other existing amine oxidase mimics, ${ }^{15}$ nonactivated aliphatic primary monoamines also proved good substrates for the catalyst $\mathbf{1}_{\mathbf{o x}}$ (Table 1, entries 2-4). In the specific case of methylamine (entry 2), the current efficiency (50\%) was roughly halved, whereas no DNPH could be detected as a result of conversion of methylamine into volatile reaction products on the time scale of anodic electrolysis. As a proof, when propylamine (entry 3) was used as the amine substrate, 30\% of DNPH could be isolated, as roughly expected on the basis of the current efficiency (70\%). Interestingly, $o$-iminoquinone $\mathbf{1}_{\mathbf{o x}}$ was 
effective in oxidizing aminoacetone (entry 4), a specific endogenous substrate for PrAOs, as the current efficiency and the yield of DNPH reached $94 \%$ and $44 \%$, respectively. Because of the instability of the free form, aminoacetone was prepared as its masked acetal according to reaction scheme 2 .

As shown in Table 1, the electrocatalyst $\mathbf{1}_{\mathbf{x}}$ exhibited the same substrate specificity as the PrAO enzymes, that is poor reactivity with $\alpha$-branched primary amines (Table 1, entry 5) and no reactivity toward secondary (Table 1 , entry 6$)$ and tertiary amines ( $\mathbf{1}_{\mathbf{o x}}$ was found to be inactive toward trimethylamine).

In a second series of experiments, we investigated the catalytic efficiency of the electrocatalyst $\mathbf{1}_{\mathbf{o x}}$ toward endogenous diamines and polyamines. Histamine and putrescine (Table 1, entries 7 and 8) were chosen as they are good substrates for DAOs. ${ }^{13,14}$, while spermidine is a substrate of the widely-studied bovine serum amine oxidase (BSAO) which remains as a member of the new PrAOs group. ${ }^{19}$ This enzyme is known to oxidize the primary amino termini of polyamines such as spermidine and spermine. ${ }^{20}$ Unfortunately, as previously reported, ${ }^{21}$ diamines and polyamines spontaneously attached to the platinum anode which, consequently, had to be replaced by a mercury pool whose potential was fixed at $0.0 \mathrm{~V}$ vs. SCE. Under these experimental conditions, high current efficiencies were obtained for the $\mathbf{1}_{\mathbf{0}} \mathbf{x}^{-}$ mediated oxidation of putrescine (entry 8) and spermidine (entry 9). However, with spermidine, no DNPH could be evidenced because the catalytic process produced an alkylimine which, under aqueous acidic conditions, afforded an unstable aldehyde. As previously reported, the latter spontaneously decomposed through a retro Michael reaction into volatile acrolein ${ }^{20}$ and putrescine, which could be isolated as an insoluble ammonium disulphate. On the basis of the current efficiency which laboriously reached $20 \%$, histamine seemed to be an inferior substrate for the biomimetic electrocatalyst $\mathbf{1}_{\mathbf{o x}}$ (entry 7). Actually, no conclusion could be drawn because of the partial adsorption of histamine on the mercury pool resulting in a rapid decrease of the current intensity.

\section{Conclusions}

The discovery that vascular adhesion protein 1 (VAP-1) is an amine oxidase and is probably a source of soluble PrAO activity, ${ }^{22}$ has stimulated a great deal of new research on the physiological roles of $\mathrm{CuAO}$ enzymes which may be more diverse than previously considered. ${ }^{1}$ Especially, these enzymes are important in the growth, development and 
metabolism of multiple organisms. ${ }^{3,7}$ Effective inhibitors of PrAOs are of current interest because of their desired applications as therapeutic agents. ${ }^{12}$ In particular, it will be highly desirable to obtain inhibitors with notable selectivity toward CuAOs over mitochondrial flavoproteins MAO-A and MAO-B. Consequently, the design of small artificial catalysts that closely approach the activity and specificity of $\mathrm{CuAOs,} \mathrm{might} \mathrm{provide} \mathrm{important} \mathrm{guidelines}$ for designing selective CuAOs inhibitors. Using diverse endogenous mono- and polyamines, we have demonstrated that the electrocatalyst $\mathbf{1}_{\mathbf{o x}}$ presents the chemoselectivity observed for the $\mathrm{CuAOs}$ enzymes that is, high reactivity with unbranched primary amines and with the primary amino group of diamines and polyamines, whereas poor reactivity with $\alpha$-branched amines. Overall, $\mathbf{1}_{\mathbf{0 x}}$ mimics not only the metabolic activity of PrAO enzymes, as high catalytic performances have been observed with primary monoamines (benzylamine, aminoacetone, propylamine and methylamine) and the terminal primary amino group of spermidine, but also that of DAOs as shown by the data obtained with putrescine, and to a lesser extent histamine. Contrary to FAD-dependent amine oxidases, no activity was observed with secondary and tertiary amines (Table 2). Finally, a last question emerges whether known selective CuAOs inhibitors can also prevent the activity of the electrocatalyst $\mathbf{1}_{\mathbf{o x}}$. This study is currently envisioned in our laboratory because, in the affirmative, this small molecule might be used for a preliminary screening of potential inhibitors of $\mathrm{CuAO}$ enzymes.

\section{Experimental Section}

${ }^{1} \mathrm{H}$ and ${ }^{13} \mathrm{C}$ NMR spectra were recorded on a Brucker AC-300 spectrometer operating at 300 $\mathrm{MHz}$ and $75 \mathrm{MHz}$, respectively. Chemicals were commercial products of the highest available purity and were used as supplied. Reduced catalyst $\mathbf{1}_{\text {red }}$ was synthesized in two steps from commercially available 2-nitroresorcinol, according to our published procedure (see the supporting information of reference 23).

\section{General procedure for the $1_{0 x}$-mediated oxidation of primary amines.}

Controlled-potential electrolysis was carried out in a cylindrical three-electrode divided cell (9 $\mathrm{cm}$ diameter), using an electronic potentiostat. In the main compartment, a platinum grid (60 $\mathrm{cm}^{2}$ area) served as the anode (working electrode). In the specific case of histamine, putrescine and spermidine (Table 1, entries 7-9), the platinum grid was replaced by a mercury 
pool because polyamines spontaneously attached to the electrode surface. ${ }^{21}$ A platinum sheet was placed in the concentric cathodic compartment (counter electrode), which was separated from the main compartment with a glass frit. The reference electrode was an aqueous saturated calomel electrode (SCE), which was isolated from the bulk solution in a glass tube with a fine-porosity frit. The electrolyte solution $\left(0.1 \mathrm{~mol} . \mathrm{L}^{-1}\right.$ lithium perchlorate in methanol) was poured into the anodic and the cathodic compartments, as well as into the glass tube that contained the SCE electrode. Reduced catalyst $\mathbf{1}_{\text {red }}(0.1 \mathrm{mmol})$ and an excess of primary aliphatic amine $(5 \mathrm{mmol})$ were then added to the solution in the main compartment $(250 \mathrm{~mL})$, and the resulting solution was oxidized, under nitrogen, at room temperature, at $+0.6 \mathrm{~V} v \mathrm{~s}$ SCE (initial current 30-40 mA). After exhaustive electrolysis, that is when a negligible current was recorded $(0.5-1.0 \mathrm{~mA})$, the solution was worked-up by the addition of 2,4dinitrophenylhydrazine reagent $\left(2.5 \mathrm{mmol}\right.$ in $5 \mathrm{~mL}$ of pure $\mathrm{H}_{2} \mathrm{SO}_{4}, 15 \mathrm{~mL}$ of EtOH, and $5 \mathrm{~mL}$ of water), ${ }^{24}$ the stoichiometry reflecting the fact that $5 \mathrm{mmol}$ of the primary amine gave only $2.5 \mathrm{mmol}$ of the $\mathrm{N}$-alkylidenealkylamine (scheme 2). After $1 \mathrm{~h}$, the resulting solution was concentrated to a volume of $40 \mathrm{~mL}$. The solid obtained was collected by filtration, washed with water and dried in a vacuum desiccator. The identity and purity of 2,4dinitrophenylhydrazone was confirmed by TLC and ${ }^{1} \mathrm{H}$ NMR spectroscopy, after comparison with an authentic sample.

\section{Acknowledgments}

We thank Dr. Andrew Holt, Associate Professor at the University of Alberta (Canada) for fruitful discussions.

\section{Notes and references}

1 For reviews, see: (a) M. Strolin Benedetti, K. F. Tipton and R. Whomsley, Fondam. Clin. Pharmacol., 2007, 21, 467; (b) A. Boobis, J.B. Watelet, R. Whomsley, M. Strolin Benedetti, P. Demoly and K. F. Tipton, Drug Metab. Rev., 2009, 41, 486. 
2 For reviews, see: (a) A. S. Kalgutkar, D. K. Dalvie, N. Castagnoli and T. J. Taylor, Chem. Res. Toxicol., 2001, 14, 1139; (b) P. F. Fitzpatrick, Arch. Biochem. Biophys., 2010, 493, 13.

3 For reviews, see: (a) J. P. Klinman, Biochim. Biophys. Acta, 2003, 1647, 131; (b) B. J. Brazeau, B. J. Johnson and C. M. Wilmot, Arch. Biochem. Biophys., 2004, 428, 22; (c) S. Suzuki, T. Okajima, K. Tanizawa and M. Mure, Cofactors of amine oxidases. Copper ion and its substitution and the 2,4,5-trihydroxyphenylalanine quinone. In Copper Amine Oxidases. Structures, Catalytic Mechanisms, and Role in Pathophysiology, ed. G. Floris and B. Mondovi, CRC Press, Taylor and Francis Group Publishing, New York, 2009; pp 19.

4 S. X. Wang, M. Mure, K. F. Medzihradszky, A. L. Burlingame, D. E. Brown, D. M. Dooley, A .J. Smith, H. M. Kagan and J. P. Klinman, Science, 1996, 273, 1078.

5 S. M. Janes, D. Mu, D. Wemmer, A. J. Smith, S. Kaur, D. Maltby, A. L. Burlingame and J. P. Klinman, Science, 1990, 248, 981.

6 S. Boyce, K. F. Tipton, M. I. O’Sullivan, G. P. Davey, M. Motherway, M. Gildea, A. G. McDonald, A. Olivieri and J. O'Sullivan, Nomenclature and potential functions of copper amine oxidases. In Copper Amine Oxidases. Structures, Catalytic Mechanisms, and Role in Pathophysiology, ed G. Floris, B. and Mondovi, CRC Press, Taylor and Francis Group Publishing, New York, 2009; pp 5. These changes are now available at http://www.enzyme-database.org.

7 For reviews see: (a) P. Dunkel, A. Gelain, D. Barlocco, N. Haider, K. Gyires, B. Sperlagh, K. Magyar, E. Maccioni, A. Fadda and P. Matyus, Curr. Med. Chem., 2008, 15, 1827; (b) F. Yraola, A. Zorzano, F. Albericio and M. Royo, ChemMedChem, 2009, 4, 495; (c) S. Kaitaneimi, H. Elovaara, K. Grön, H. Kidron, J. Liukkonen, T. Salminen, M. Salmi, S. Jalkanen and K. Elima, Cell. Mol. Life Sci., 2009, 66, 2743.

8 For reviews, see: (a) G. A. Lyles, Int. J. Biochem. Cell. Biol., 1996, 28, 259; (b) P. H. Yu, S. Wright, E. H. Fan, Z. R. Lun and D. Gubisne-Harberle, Biochim. Biophys. Acta, 2003, 1647, 193; (c) P. Matyus, B. Dajka-Halasz, A. Földi, N. Haider, D. Barlocco, K. Magyar, Curr. Med. Chem., 2004, 11, 1285; (d) J. O’Sullivan, M. Unzeta, J. Healy, M. O’Sullivan, G. Davey and K. T. Tipton, Neurotoxicology, 2004, 25, 303. 
9 F. Boomsma, U. M. Bhaggoe, A. M. B. Van der Houwen and A. H. Van den Meiracker, Biochim. Biophys. Acta, 2003, 1647, 48.

10 T. Obata, Life Sci., 2006, 79, 417 and references therein.

11 (a) P. H. Yu, Med. Hypothesis, 2001, 57, 175; (b) M. Hernandez, M. Esteban, P. Szabo, M. Boada and M. Unzeta, Neuroscience Lett., 2005, 384, 183; (c) K. Chen, J. Maley and P .H. Yu, J. Neurochem., 2006, 99, 1413; (d) Z. J. Jiang, J. S. Richardson and P. H. Yu, Neuropathol. Appl. Neurobiol., 2008, 34, 194.

12 A. M. O’Rourke, E. Y. Wang, A. Miller, E. M. Podar, K. Scheyhing, L. Huang, C. Kessler, H. Gao, H. T. Ton-Nu, M. T. MacDonald, D. S. Jones and M. D. Linnik, J. Pharmacol. Exp. Ther., 2008, 324, 867.

13 For a review see: E. Agostinelli, G. Arancia, L. Dalla Vedova, F. Belli, M. Marra, M. Salvi and A. Toninello, Amino acids, 2004, 27, 347.

14 For reviews see: (a) P. Pietrangeli and B. Mondovi, Neurotoxicology, 2004, 25, 317. (b) A. Toninello, P. Pietrangeli, U. De Marchi, M. Salvi and B. Mondovi, Biochim. Biophys. Acta, 2006, 1765, 1; (c) E. Agostinelli, G. Tempera, A. Molinari, M. Salvi, V. Battaglia, A. Toninello and G. Arancia, Amino acids, 2007, 33, 175; (d) E. Agostinelli, G. Tempera, N. Viceconte, S. Saccoccio, V. Battaglia, S. Grancara, A. Toninello and R. Stevanato, Amino acids, 2010, 38, 353.

15 For a review see: (a) A. C. Rinaldi, A. Rescigno, A. Rinaldi and E. Sanjust, Bioorg. Chem., 1999, 27, 253; see also: (b) M. Mure and J. P. Klinman, J. Am. Chem. Soc., 1995, 117, 8707; (c) Y. Lee and L. M. Sayre, J. Am. Chem. Soc., 1995, 117, 11823 and references therein. (d) K. Q. Ling, J. Kim and L. M. Sayre, J. Am. Chem. Soc., 2001, 123, 9606; (e) M. Mure, S. X. Wang and J. P. Klinman, J. Am. Chem. Soc., 2003, 125, 6113.

16 (a) M. Mure, S. A. Mills and J. P. Klinman, Biochemistry, 2002, 41, 9269; (b) P. Pietrangeli, S. Nocera, B. Mondovi and L. Morpugo, Biochem. Biophys. Acta-Proteins Proteomics, 2003, 1647, 152; (c) M. Mure, Acc. Chem. Res., 2004, 37, 131; (d) J. L. Dubois and J. P. Klinman, Arch. Biochem. Biophys., 2005, 433, 255; (e) E. Agostinelli, F. Belli, L. Dalla Vedova, S. Longu, A. Mura and G. Floris, Eur. J. Inorg. Chem., 2005, 1635; (f) E. M. Shepard and D. M. Dooley, J. Biol. Inorg. Chem., 2006, 11, 1039; (g) G. A. 
Juda, E. M. Shepard, B. O. Elmore and D. M. Dooley, Biochemistry, 2006, 45, 8788; (h) R. W. D. Welford, A. Lam, L. M. Mirica and J. P. Klinman, Biochemistry, 2007, 46, 10817.

17 (a) M. Largeron and M.-B. Fleury, J. Org. Chem., 2000, 65, 8874; (b) M. Largeron, A. Neudörffer and M.-B. Fleury, Angew. Chem. Int. Ed., 2003, 42, 1026; (c) M. Largeron, A. Chiaroni and M.-B. Fleury, Chemistry-Eur. J., 2008, 14, 996.

18 (a) R. Calabretta, C. Giordano, C. Gallina, V. Morea, V. Consalvi and R. Scandurra, Eur. J. Med. Chem., 1995, 30, 931; (b) P. Cui, T. L. Macdonald, M. Chen and J. L. Nadler, Bioorg. Med. Chem. Lett., 2006, 16, 3401.

19 For a recent review see: (a) P. Pietrangeli, L. Morpurgo, B. Mondovi, M. L. Di Paolo and A. Rigo, Soluble copper amine oxidases from mammals. In Copper Amine Oxidases. Structures, Catalytic Mechanisms, and Role in Pathophysiology, ed G. Floris and B. Mondovi, Eds.; CRC Press, Taylor and Francis Group Publishing, New York, 2009; pp 51. See also: (b) G. Houen, C. Struve, R. Sondergaard, T. Friis, U. Anthoni, P.H. Nielsen, C. Christophersen, B. O. Petersen and J. O. Duus, Bioorg. Med. Chem., 2005, 13, 3783; (c) K.-Q. Ling and L.M. Sayre, J. Org. Chem., 2009, 74, 339.

20 Y. Lee and L. M. Sayre, J. Biol. Chem., 1998, 273, 19490.

21 I. Gallardo, J. Pinson and N. Vilà, J. Phys. Chem. B, 2006, 110, 19521.

22 K. Jaakkola, S. Jalkanen, K. Kaunismäki, E. Vänttinen, P. Saukko, K. Alanen, M. Kallajoki, L. M. Voipio-Pulkki and M. Salmi, J. Am. Coll. Cardiol., 2000, 36, 122.

23 D. Xu, A. Chiaroni, M.-B. Fleury and M. Largeron, J. Org. Chem., 2006, 71, 6374. 24 P. Lue, W. Q. Fan and X. J. Zhou, Synthesis, 1989, 692. 


\section{Captions to Figure and Schemes}

Fig. 1 Chemical structures of flavine adenine dinucleotide (FAD), topaquinone (TPQ), lysine tyrosylquinone (LTQ) redox cofactors, together with CuAOs mimic $\mathbf{1}_{\mathbf{o x}}$.

Scheme $1 \mathbf{1}_{\mathbf{o x}}$-mediated catalytic oxidation of primary aliphatic amines into imines.

Scheme 2 Synthesis of aminoacetone as its masked acetal form ${ }^{18}$. 
Table $11_{\text {ox }}$-mediated oxidation of CuAOs mono- and polyamine substrates ${ }^{a}$

$\begin{array}{lllll}\text { Entry Amine substrate } \begin{array}{l}\text { Produced } \\ \text { aldehyde }\end{array} & \begin{array}{l}\text { Current } \\ \text { efficiency }\end{array} & \begin{array}{c}\text { Yield of } \\ \text { DNPH (\%) } \\ \text { vs Amine }\end{array} \\ \text { vs 1 } \mathbf{1}_{\text {ox }}\end{array}$

${ }^{a}$ Reagents and c.p.e. conditions: $\left(\mathbf{1}_{\text {red }}\right)=0.4 \mathrm{mM}$, (amine substrate $)=20 \mathrm{mM}, \mathrm{MeOH}, \mathrm{rt}$, Pt anode $(\mathrm{E}=+0.6 \mathrm{~V} v s \mathrm{SCE}) .{ }^{b}$ Volatile reaction products were lost during the anodic electrolysis. ${ }^{c}$ The Pt anode was replaced by a $\mathrm{Hg}$ anode $(\mathrm{E}=0.0 \mathrm{~V} v s$ SCE) because polyamines spontaneously attached to the Pt electrode surface. ${ }^{21 d}$ No DNPH could be isolated. ${ }^{d}$ Putrescine was isolated as an insoluble ammonium disulphate, the sole reaction product. 
Table 2 Substrate specificity for amine oxidase enzymes in comparison with mimic $\mathbf{1}_{\mathbf{o x}}$

\begin{tabular}{|c|c|c|c|c|c|}
\hline \multirow[t]{2}{*}{ Substrate } & \multicolumn{2}{|c|}{$\begin{array}{l}\text { FAD-Dependent } \\
\text { Enzyme }\end{array}$} & \multicolumn{2}{|c|}{$\begin{array}{l}\text { TPQ Dependent } \\
\text { Enzyme }\end{array}$} & \multirow{2}{*}{$\begin{array}{c}\text { Mimic } \\
\mathbf{1}_{\mathbf{o x}}\end{array}$} \\
\hline & MAO & PAO & PrAO & DAO & \\
\hline Primary amine & $x$ & - & $x$ & $x$ & $x$ \\
\hline Secondary amine & $x$ & - & - & - & - \\
\hline Tertiary amine & $x$ & - & - & - & - \\
\hline Diamine & - & - & - & $x$ & $x$ \\
\hline $\begin{array}{l}\text { Polyamine } \\
\text { (primary } \\
\text { amino group) }\end{array}$ & - & - & $\begin{array}{c}\times \\
(B S A O)\end{array}$ & - & $x$ \\
\hline $\begin{array}{l}\text { Polyamine } \\
\text { (secondary } \\
\text { amino group) }\end{array}$ & - & $x$ & - & - & - \\
\hline
\end{tabular}

( $\times$ ) catalytic activity; (-) no catalytic activity. BSAO : Bovine serum amine oxidase 